\title{
Introduction: studies on the learning process in the one-day, one-problem approach to problem-based learning
}

\author{
Jerome I. Rotgans • Glen O'Grady • W. A. M. Alwis
}

Received: 31 August 2010/Accepted: 15 April 2011/Published online: 17 May 2011

(C) The Author(s) 2011. This article is published with open access at Springerlink.com

\section{One-day, one-problem}

\section{Setting}

Problem-based learning (PBL) as a method of instruction in the health sciences has attracted considerable attention over the years (Barrows 1996; Colliver 2000; Norman 2002). Research in this field has predominantly focused on curriculum comparisons between PBL and more conventional instructional methods, with only limited interest in what happens to the learner in PBL (ten Cate 2001). The seven papers comprising this special issue all focus on the latter: research on the learning process in PBL. The research to be presented here took place in the context of a new polytechnic in Singapore: the Republic Polytechnic. This polytechnic employs an unconventional version of PBL across its educational programs. The PBL approach the polytechnic developed and implemented is referred to as the one-day, one-problem approach (Alwis and O'Grady 2002).

Republic Polytechnic, Singapore

Republic Polytechnic is the fifth and latest polytechnic established in 2002 by the Government of Singapore. The purpose of the polytechnic is to provide pre-employment training to post-secondary students by means of 3-year diploma programs. The polytechnic offers in total about 35 diploma programs, which are predominantly of technical nature, including life sciences, health sciences, engineering, and information technology. When entering the polytechnic, students are typically 17 years of age and have generally not been exposed to PBL before.

\section{J. I. Rotgans ( $\square)$}

Centre for Research in Pedagogy and Practice, National Institute of Education,

Nanyang Technological University, 1 Nanyang Walk, Singapore 637616, Singapore

e-mail: rotgans@gmail.com

G. O'Grady - W. A. M. Alwis

Centre for Educational Development, Republic Polytechnic,

9 Woodlands Avenue 9, Singapore 738964, Singapore 
Characteristics of the one-day, one-problem approach

As the name implies, students work on one problem each day. Each day covers a different subject, for instance, on every Monday students work an entire day only on subject A, on Tuesday they work an entire day on subject B, on Wednesday on subject $\mathrm{C}$, and so on. It is argued that this modular structure enables students to avoid divided attention, that is, to fully focus on one single subject or topic each day without having to worry about another subject or having to mentally switch between subjects during the day.

This is what happens during a typical day. A class, consisting out of five teams of five students, meets three times under the guidance of a tutor. All students have a laptop computer with which they access the school's intranet. The problems, learning materials, and assessments are accessible via this e-platform. The day starts with the presentation of a problem. Based on the problem, students in their small groups activate their prior knowledge, come up with tentative theories to explain the phenomena presented in the problem, and formulate their own learning goals. Subsequently, a short self-study period of about an hour follows during which students individually conduct an initial literature search. After this, students meet for a second time during the day to share insights gained during the short self-study period and-if necessary—make amendments to their learning goals. At this stage, the tutor will meet and talk with each group to check on their progress, challenge their explanations, and to provide scaffolding if needed. After this second meeting students engage in a second and longer self-study period (about $2 \mathrm{~h}$ ), during which they individually search for information, read the literature, and prepare notes. Essential study materials are provided and accessible via the e-platform. At the end of the self-study period the teams meet and prepare a presentation summarizing and synthesizing their findings. After the self-study period the class meets again and each team shares their findings with the entire class. During this final meeting students engage in discussions, questioning each other's explanations, and elaborate on their findings. As such, the third meeting concludes the one-day, one-problem cycle and students begin the next day working on a new problem.

One-day, one-problem versus conventional PBL

In conventional PBL, small groups of around nine students typically meet two or three times a week under the guidance of a tutor. They receive a problem, which is the starting point of the learning process. The problems are typically neutral descriptions of phenomena in need of explanation. Based on students' discussion about the problem, they generate their own learning goals for subsequent self-directed learning. After a period of self-study, students share what they have learned about the topic and test whether their new understanding of the problem is now more accurate and elaborate than before. Once students are satisfied with their learning outcomes, they engage with a new problem and the cycle starts all over again (Barrows 1985; Hmelo-Silver 2004; Schmidt 1983, 1993; Schmidt et al. 2009).

The one-day, one-problem approach fits the above description, except that the PBL cycle is compressed to one day with more structural mechanisms to provide guidance to the students. The overall rationale behind this shortened one-day version of PBL is that students in polytechnic education are generally not so mature and independent learners as may be the case for university students in general and medical students in particular. Allowing polytechnic students to work on one or two problems a week, as it is typically the case in PBL curricula, was expected to result in problems such as procrastination or high 
absenteeism. Since these students are generally young it was expected that they need more structure and guidance in their learning. The one-day, one problem approach provides structure and guidance because (1) students only have to concentrate on one topic for the duration of one day, which allows them to work on smaller and more manageable "learning units"; (2) guidance is provided by splitting the day up into three meetings during which the tutor can closely monitor students' progress and if necessary intervene to guide them towards the right track. As such, the tutor in the one-day, one-problem approach may monitor (and if necessary influence) students' progress more closely than in conventional PBL.

Since the one-day, one-problem approach provides more structure to learning process it appears as an attractive alternative to conventional PBL, particularly for younger students in secondary schools or polytechnic education.

\section{Research}

From the early beginnings, numerous studies have been conducted around the one-day, one-problem approach to investigate its effects on student learning and achievement. Seven of these studies, all recently conducted, are reported in this special issue. Most of these studies were conducted in the context of health and life sciences. The studies address current issues in the PBL literature and go beyond the one-day, one-problem approach. To present the articles in a somewhat logical manner, we arranged them into two broad categories: (1) Research on how students learn in PBL and (2) Research on the factors that influence student learning in $P B L$. The first category is about the core processes of student learning in PBL. For instance, how do students construct their knowledge in PBL? Or, are there variations in students' cognitive engagement during the PBL cycle? And if so, what causes them? These are issues that fall under this category. The second category is about factors that influence the core learning processes - that is, the influence problems, tutors, or learning scaffolds have on student learning in PBL are addressed.

\section{Research on how students learn in PBL}

The first two studies cast some light on how students learn during the PBL process itself, in real time. Since conventional survey methods are rather limited in measuring actual classroom dynamics (i.e. surveys are typically administered before and/or after class) more micro-analytical measurement techniques are needed (Rotgans and Schmidt 2011a, b). For instance, both studies sampled data at not only one point in time, but several times at critical moments during the PBL process to determine how students' learning develops over the course of the learning event. Considering that the bulk of studies reported in the PBL literature tend to favor curriculum comparison studies between PBL and more conventional settings (Albanese 2000; Dochy et al. 2003; McParland et al. 2004; Schmidt et al. 2009; Schmidt et al. 2005; Vernon and Blake 1993), we see these studies as a welcome addition to the literature, because they provide insights in the actual learning processes in PBL.

The first study by Yew, Chng, and Schmidt addresses the question whether learning in PBL is cumulative, that is, does one learning phase in PBL builds on a previous one. For instance, does what was learned during the problem analysis phase determine the knowledge gained during individual self-study and does this determine the knowledge gained during the reporting phase. Although it is generally widely accepted that the 
acquisition of knowledge depends on what was learned previously (Alexander et al. 1994), proof of this fact is mainly restricted to laboratory experiments; whether that is the case in the naturalistic classroom environment remains to be seen. Moreover, it is not very clear whether students in PBL acquire most of their knowledge during the collaborative interactions in the tutorial group or during individual self-study, or a combination of both. On the one hand, social constructivist theories suggest that knowledge is mainly constructed by means of collaborative interactions (Driver et al. 1994) and on the other hand selfregulated learning theories postulate that knowledge is acquired independently through self-regulation of one's motivational beliefs and the use of adaptive learning strategies (Paris and Paris 2001). In this article the authors propose and tested a model, which provides insights in how collaborative group work and independent self-study interact and build on each other in PBL.

The second study by Rotgans and Schmidt is about students' cognitive engagement during PBL. Similar to the first study, this study examined how students' cognitive engagement develops also as a function of the PBL phases. With this study the authors empirically tested a common underlying assumption that students in PBL would feel more autonomous and empowered because they have a choice in what they learn (i.e. they formulate their own learning goals). According to self-determination theory (Deci et al. 1991; Ryan and Deci 2000), having choice and autonomy to determine what to study should result in higher levels of cognitive engagement. In this study the authors examined under which conditions do students in PBL feel more autonomous and engage more cognitively with the task at hand.

Research on the factors that influence student learning in PBL

The second batch of papers reported in this special issue address topics that influence student learning in one way or the other. For instance, recurring and important topics in the PBL literature is the research related to the effectiveness of problems and the significant role tutors play in PBL. More recently however, new topics emerged, such as the role of scaffolds to structure student learning and students' self-reflection in PBL (Hmelo-Silver 2004; Hmelo-Silver et al. 2007; Simons and Klein 2007; Williams 2001).

We begin with the problems. The third study in this issue examined how distinct problem characteristics, such as problem familiarity and problem clarity, influence student learning and achievement in PBL. Sockalingam, Rotgans, and Schmidt propose that there are several studies in the PBL literature which looked at the influence problems have on students learning (Schmidt et al. 1995; Schmidt and Moust 2000), but they are limited in a sense that they did not identify which specific problem characteristics are responsible for student learning in PBL. A potential problem with the existing studies is that researchers typically aggregate all items pertaining to one multi-dimensional scale, often labeled "quality of problems". The authors argue for a more detailed measurement approach in which they analyzed the data at item level. In their study they devised a causal model to test how individual problem characteristics (i.e. individual items) influence student learning and achievement.

The fourth study by Chng, Yew, and Schmidt examines the effects of tutor-related behaviors on the PBL process. They operationalized tutor-related behaviors by means of Moust's early causal model of PBL (Moust 1993) in which social congruence, subjectmatter expertise, and cognitive congruence are the key components. Although these three distinct tutor-related behaviors have been examined in numerous studies over the years, little is known of how they impact students' knowledge construction. With this study the 
authors applied a microanalytical approach, similar to the first two studies, and measured students' knowledge construction at critical phases in the learning process. This enabled them to examine which of the tutor-related behaviors have the most significant effect on students' knowledge constructing and when that occurs during PBL.

The fifth study by Williams and Rotgans, is related to the previous study in the sense that the authors also used the variables social congruence, subject-matter expertise, and cognitive congruence in their investigation. However, the central issue in this study is whether these tutor variables are stable across time and context. This is an important subject because it provides more insights in the role tutors have in PBL and how consistent their behaviors are in facilitating student learning. In the study, the authors applied a repeated measurement approach over three semesters to examine how stable the tutor variables really are.

The next study investigated the effects worksheet scaffolds have on student learning in PBL. This study from Choo and colleagues cast some light on the question of how much guidance and structure do students need in PBL. The question on how much guidance is needed in PBL caused quite some debate in the PBL literature (Hmelo-Silver, et al. 2007; Kirschner et al. 2006). Some researchers have argued that scaffolds, such as worksheets, benefit students who are novices to PBL and provide necessary cognitive support when working on the problems. Generally, the literature remains however inconclusive whether scaffolds are effective means to structure student learning in PBL. There is a lack of experimental studies that can pinpoint the effects of scaffolds on student learning in PBL. In this study, the authors applied a quasi-experimental approach, in which they compared the effects worksheets have on student learning and their academic achievement.

The final study also addresses a topic, which was subject of recent debate: The link between self-reflection and academic performance (Williams 2001). In other words, how effective is self- and critical-reflection in helping students in their learning. In this study Lew and Schmidt extracted reflection journals from PBL students at the beginning and the end of the semester and subjected them to a content analysis to identify whether students do indeed reflect on their learning. Furthermore they correlated the concept frequencies with students' academic achievement to examine if students who reflect on their learning do indeed perform better academically.

Considering that the structure of the one-day, one-problem approach at the polytechnic is not different from conventional PBL in the sense that students still have a problem trigger as the starting point of their learning process, engage in collaborative group discussions, formulate hypotheses about the problem, engage in independent self-study, and elaborate on their findings, we expect that the results of the studies reported in this special issue can largely be generalized to conventional PBL and hope will trigger further studies devoted to the investigation of the learning process in PBL.

Open Access This article is distributed under the terms of the Creative Commons Attribution Noncommercial License which permits any noncommercial use, distribution, and reproduction in any medium, provided the original author(s) and source are credited.

\section{References}

Albanese, M. (2000). Problem-based learning: Why curricula are likely to show little effect on knowledge and clinical skills. Medical Education, 34(9), 729-738.

Alexander, P. A., Kulikowich, J. M., \& Jetton, T. L. (1994). The role of subject-matter knowledge and interest in the processing of linear and nonlinear texts. Review of Educational Research, 64(2), 201-252.

Alwis, W. A. M., \& O’Grady, G. (2002). One day-one problem at Republic Polytechnic. In Paper presented at the 4th Asia-Pacific conference on PBL. 
Barrows, H. S. (1985). How to design a problem-based curriculum for the preclinical years. New York: Springer.

Barrows, H. S. (1996). Problem-based learning in medicine and beyond: A brief overview. New directions for teaching and learning, 1996(68), 3-12.

Colliver, J. (2000). Effectiveness of problem-based learning curricula: Research and theory. Academic Medicine, 75(3), 259.

Deci, E. L., Vallerand, R. J., Pelletier, L. G., \& Ryan, R. M. (1991). Motivation and education: The selfdetermination perspective. Educational Psychologist, 26(3\&4), 325-346.

Dochy, F., Segers, M., Van den Bossche, P., \& Gijbels, D. (2003). Effects of problem-based learning: A meta-analysis. Learning and Instruction, 13(5), 533-568.

Driver, R., Asoko, H., Leach, J., Scott, P., \& Mortimer, E. (1994). Constructing scientific knowledge in the classroom. Educational Researcher, 23(7), 5-12.

Hmelo-Silver, C. E. (2004). Problem-based learning: What and how do students learn? Educational Psychology Review, 16(3), 235-266.

Hmelo-Silver, C. E., Duncan, R. G., \& Chinn, C. A. (2007). Scaffolding and achievement in problem-based and inquiry learning: A response to Kirschner, Sweller, and Clark (2006). Educational Psychologist, 42(2), 99-107.

Kirschner, P. A., Sweller, J., \& Clark, R. E. (2006). Why minimal guidance during instruction does not work: An analysis of the failure of constructivist, discovery, problem-based, experiential, and inquirybased teaching. Educational Psychologist, 41(2), 75-86.

McParland, M., Noble, L., \& Livingston, G. (2004). The effectiveness of problem-based learning compared to traditional teaching in undergraduate psychiatry. Medical Education, 38(8), 859-867.

Moust, J. H. C. (1993). De rol van tutoren in probleemgestuurd onderwijs (The role of tutors in problembased learning). Maastricht: Maastricht University.

Norman, G. T. (2002). Research in medical education: Three decades of progress. British Medical Journal, 324(7353), 1560-1562.

Paris, S. G., \& Paris, A. H. (2001). Classroom applications of research on self-regulated learning. Educational Psychologist, 36(2), 89-101.

Rotgans, J. I., \& Schmidt, H. G. (2011a). Situational interest and academic achievement in the activelearning classroom. Learning and Instruction, 21(1), 58-67.

Rotgans, J. I., \& Schmidt, H. G. (2011b). The role of teachers in facilitating situational interest in an activelearning classroom. Teaching and Teacher Education, 27(1), 37-42.

Ryan, R. M., \& Deci, E. L. (2000). Self-determination theory and the facilitation of intrinsic motivation, social development, and well-being. American Psychologist, 55(1), 68-78.

Schmidt, H. G. (1983). Problem-based learning: Rationale and description. Medical Education, 17(1), $11-16$.

Schmidt, H. G. (1993). Foundations of problem-based learning: Some explanatory notes. Medical Education, 27(5), 422-432.

Schmidt, H. G., Cohen-Schotanus, J., \& Arends, L. R. (2009a). Impact of problem-based, active learning on graduation rates for 10 generations of Dutch medical students. Medical Education, 43(3), 211-218.

Schmidt, H. G., Dolmans, D., Gijselaers, W. H., \& Des Marchais, J. E. (1995). Theory-guided design of a rating scale for course evaluation in problem-based curricula. Teaching and Learning in Medicine, 7(1), 82.

Schmidt, H. G., \& Moust, J. H. C. (2000). Factors affecting small-group tutorial learning: A review of research. In D. H. Evensen \& C. E. Hmelo-Silver (Eds.), Problem-based learning: A research perspective in learning interactions (pp. 19-52). Mahwah, NJ: Lawrence Erlbaum.

Schmidt, H. G., Van der Molen, H. T., Te Winkel, W. W. R., \& Wijnen, W. H. F. W. (2005). Constructivist, problem-based learning does work: A meta-analysis of curricular comparisons involving a single medical school. Educational Psychologist, 44(4), 227-249.

Schmidt, H. G., Van der Molen, H. T., Te Winkel, W. W. R., \& Wijnen, W. H. F. W. (2009b). Constructivist, problem-based, learning does work: A meta-analysis of curricular comparisons involving a single medical school. Educational Psychologist, 44(4), 227-249.

Simons, K., \& Klein, J. (2007). The impact of scaffolding and student achievement levels in a problembased learning environment. Instructional Science, 35(1), 41-72.

ten Cate, O. (2001). What happens to the student? The neglected variable in educational outcome research. Advances in Health Sciences Education, 6(1), 81-88.

Vernon, D., \& Blake, R. (1993). Does problem-based learning work? A meta-analysis of evaluative research. Academic Medicine, 68(7), 550-563.

Williams, B. (2001). Developing critical reflection for professional practice through problem-based learning. Journal of Advanced Nursing, 34(1), 27-34. 